\title{
The acaricidal effect of flumethrin, oxalic acid and amitraz against Varroa destructor in honey bee (Apis mellifera carnica) colonies
}

\author{
Maja Ivana Smodiš Škerl, Mitja Nakrst, Lucija Žvokelj, Aleš Gregorc \\ Agricultural Institute of Slovenia, Ljubljana, Slovenia \\ Received February 5, 2010 \\ Accepted June 15, 2010
}

\begin{abstract}
During 2007 and 2008, natural mite mortality was recorded in honey bee colonies. These colonies were then treated with various acaricides against Varroa destructor and acaricide efficacies were evaluated. In 2007, experimental colonies were treated with flumethrin and/or oxalic acid and in 2008 the same colonies were treated with flumethrin, oxalic acid or amitraz. The efficacy of flumethrin in 2007 averaged $73.62 \%$ compared to $70.12 \%$ for three oxalic acid treatments. In 2008 , a reduction of $12.52 \%$ in mite numbers was found 4 weeks after flumethrin application, while 4 oxalic acid applications produced significantly higher $(P<0.05)$ mite mortality, an average of $24.13 \%$. Four consecutive amitraz fumigations produced a $93.82 \%$ reduction on average in final mite numbers and thus ensure normal colony development and overwintering. The study is important in order to demonstrate that synthetic acaricides should be constantly re-evaluated and the use of flumethrin at low efficacies need to be superseded by appropriate organic treatments to increase the efficacy of mite control in highly-infested colonies during the period of brood rearing.
\end{abstract}

Varroa control, mite mortality, efficacy, trickling, fumigation, organic treatment

The ectoparasitic mite Varroa destructor is a major pest of honey bees (Apis mellifera) worldwide (Sammataro et al. 2000) that needs to be controlled because untreated colonies die within a few years due to damage to both pupae and adult bees (Elzen et al. 2000). A high rate of mite infestation in honey bee colony and a poor colony management have important influence on the beekeeping. Regular treatment of honey bee colonies with acaricides allows productivity to be maintained, but the use of synthetic acaricides with their lipophilic and persistent characteristics can result in their residues in wax and honey (Wallner 1999).

The synthetic pyrethroid acaricide flumethrin (Bayvarol ${ }^{\circledR}$; Bayer, Germany) is the only registered treatment against $V$. destructor for colonies with brood in Slovenia. It is relatively non-toxic to the bees and easy to use. Mites have developed resistance to several synthetic acaricides (Lodesani et al. 1995; Milani 1999; Floris et al. 2001; Spreafico et al. 2001), so beekeepers turn to alternative treatments incorporating essential oils or organic acids (Mutinelli et al. 1997; Gregorc and Poklukar 2003). Resistance of mites to acaricides has been associated with the misuse of agricultural formulations of synthetic pyrethroids (Watkins 1997). The permanent use of varroacide strips causes increasing selection pressure for resistant mites (Milani 1999).

Oxalic acid is a natural constituent of honey, and EU regulations permit its use in biological beekeeping (EU Council Regulation, No. 1804/1999). Because of its high efficacy, oxalic acid is widely used in most European countries (Charriere and Imdorf 2002). Research has been conducted into the efficacy of oxalic acid applications for controlling mites in colonies with or without brood (Imdorf et al. 1996; Brødsgaard et al. 1999).

Experiments demonstrated that trickling an aqueous oxalic acid solution into the hive (Mutinelli et al. 1997; Gregorc and Planinc 2001; Gregorc and Planinc 2002) during broodless periods (Radetzki 1994; Imdorf et al. 1997) was highly effective in killing the mite, achieving a mean $98 \%$ effectiveness. When capped brood is present, efficacy after 3

Address for correspondence:

Maja Ivana Smodiš Škerl

Agricultural Institute of Slovenia

Hacquetova 17, 1001 Ljubljana, Slovenia
Phone +386 $1280-52-41$

Fax +386 $1280-52-55$

E-mail: Maja.Smodis.Skerl@kis.si

http://www.vfu.cz/acta-vet/actavet.htm 
treatments of a 5\% oxalic acid solution was approximately 95\% (Mutinelli et al. 1997). In our previous experiments, $50 \mathrm{ml}$ of an oxalic acid solution applied to one normally developed colony had an efficacy of $39.2 \%$ when brood was present and $99.4 \%$ without brood (Gregorc and Planinc 2001). Several compounds were used against varroa mites in honeybee colonies. Amitraz, a formamidine, was successfully used to kill varroa mites when formulated as a balsa wood strip soaked in amitraz, aerosol spray or smoking paper strip (Witherell and Herbert 1988) and the organophosphate coumaphos (Perizin ${ }^{\circledR}$ ) was used to document the respective efficacies of experimentally applied acaricides (Trouiller 1998).

The aim of this study was to establish the effectiveness of amitraz, flumethrin and oxalic acid treatments for controlling $V$. destructor in honey bee colonies. We also aimed to establish an optimal strategy for summer treatment with different acaricides in colonies with brood and for winter treatments of broodless colonies.

\section{Materials and Methods}

Apis mellifera carnica colonies in hives containing ten combs $(41 \times 26 \mathrm{~cm})$ in each brood chamber and honey super were located at one site at the experimental station of the Slovenian Agricultural Institute. On 2 April 2007, metal sheets $(38 \times 29.8 \mathrm{~cm})$ were placed on the floor of each of the hives to record the colony's natural mite mortality. Wire screens above the sheet prevent bees from coming in contact with debris. The number of mites was recorded on 14 occasions in the pre-treatment period, and then recorded once a week after 7 August when treatments began.

The number of oxalic acid treatments in each colony was determined after establishing the mite mortality before and after each treatment. The colonies received $5 \mathrm{ml}$ (per comb occupied by bees) of a $2.9 \%$ oxalic acid and $31.9 \%$ sucrose aqueous solution (w/w), using oxalic acid dihydrate (Riedel-de Haën), sucrose and de-mineralised water (Gregorc and Planinc 2001). The oxalic acid treatments were applied to the experimental colonies by trickling the oxalic acid solution over the combs in situ and squirting the bees in the brood chamber using a syringe. Respiration masks, protective glasses and rubber gloves were worn while applying the solution. The mite drop during the treatment period was recorded after each application. The outside temperatures during the July and August ranged from 28 to $31^{\circ} \mathrm{C}$, and temperatures during the treatments in the broodless period were above $5^{\circ} \mathrm{C}$ in both years.

The treatments of 51 colonies in 2007 were performed as follows: Group A (43 colonies) received flumethrin strips ( 4 strips per brood chamber) between 7 and 28 August during the brood period and 2 oxalic acid treatments in the broodless period on 26 November and 13 December; Group B (eight colonies) received 3 oxalic acid treatments on 7, 22 and 28 August during the brood period, and also 2 oxalic acid treatments on 26 November and 13 December during the broodless period. Oxalic acid treatments in broodless colonies were considered as treatments to establish the final mite drop (Gregorc and Planinc 2001).

In the spring of 2008, metal sheets were placed on the floor of each hive on 13 May, and the number of mites was recorded on 11 occasions in the pre-treatment period and then regularly after the start of treatments on 25 July. The treatment groups in 2008 were different from the previous year and were as follows: Group A (28 colonies) received flumethrin between 25 July and 21 August; Group B (18 colonies) received four oxalic acid treatments 25 and 31 July and 7 and 14 August. After receiving flumethrin or oxalic acid, both groups of colonies were treated with amitraz. Each treated colony was fumigated using $0.1 \mathrm{ml}$ (3 drops) of $12.5 \%$ emulsifiable concentrate amitraz (Tactik ${ }^{\mathbb{R}}$ ) on 21 August, 11 and 22 September and 7 October.

The efficacy of the flumethrin and oxalic acid treatments, expressed as \% mite mortality, was established after each treatment, and the mean mite drop values of the treated groups were compared. A standard treatment with coumaphos (Perizin ${ }^{\circledR} 1 \mathrm{ml}$ and $15 \mathrm{~g}$ sugar in $50 \mathrm{ml}$ water; Bayer; $32 \mathrm{mg}$ coumaphos $/ 1 \mathrm{ml} \mathrm{Perizin}{ }^{\circledR}$ ) was conducted on 4 and 11 November 2008 in order to establish the final mite drop (Trouiller 1998). To estimate the percentage of mites killed (PMK) by the first flumethrin or oxalic acid application (PMK1) when brood was present, the following formula (Gregorc and Planinc 2001) was used:

$\mathrm{PMK} 1=(\mathrm{T} 1 /(\mathrm{T} 1+\mathrm{T} 2+\mathrm{T} 3+\ldots . .+\mathrm{P}) \times 100) \%$

T1, T2 and T3 denote the total number of mites that dropped after the first, second and third treatments respectively, including the flumethrin treatment (Group A), and P denotes the number of mites collected after the coumaphos treatment. The formula was modified to calculate the percentage of mites dropped after each consecutive treatment (PMK-T2 - PMK-P) by excluding the number of mites collected in the previous treatments. The efficacy of the treatments was also estimated by comparing the numbers of mites that fell before and after the treatments and the mite mortality between the consecutive oxalic acid treatments and between groups A and B. The data analyses were performed by ANOVA (analysis of variance) with the use of the Statgraphic (20) program. 


\section{Results}

During the pre-treatment periods, a total of 127 days at intervals between 2 April and 7 August 2007, the average daily natural mite drop was estimated to be $0.11( \pm 0.14)$. The average mite mortality per colony during the pre-treatment period was estimated to be $13.92( \pm 18.01)$ mites. In this period $1.12 \%( \pm 0.86 \%)$ of the total mite population found during the experiment died naturally.

Mite mortality after flumethrin application in the period from 7 to 22 August was higher $(P<0.05)$ compared to natural mite mortality in the pre-treatment period. The increase in mite mortality $(P<0.05)$ compared to pre-treatment period was found also in colonies after three oxalic acid applications. The total number of fallen mites during the experiment was not significantly $(P>0.05)$ different between the flumethrin and oxalic acid treatment groups.

The relative mite mortality in the period between 7 August and 26 November during the brood period as a result of flumethrin treatment in colonies of Group A ranged from $41.37 \%$ to $97.64 \%$ with a mean of $73.62 \%$. The corresponding three oxalic acid treatments resulted in an efficacy of between $47.68 \%$ and $98.83 \%$ with a mean of $70.12 \%$. Relative mite mortality in the 2007 experiment is shown in Fig. 1.

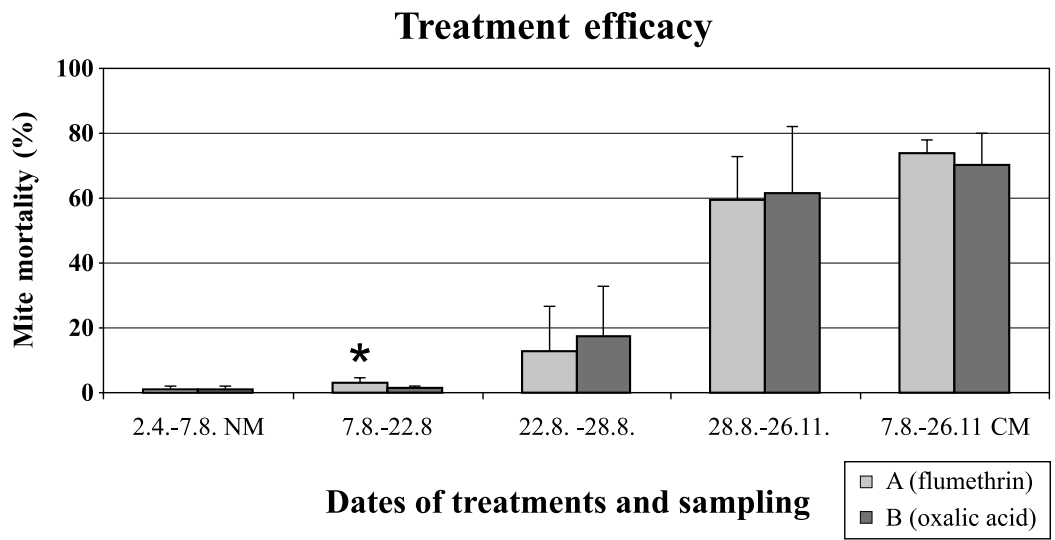

Fig. 1. Relative mite mortality after flumethrin and consecutive oxalic acid treatments, showing: natural mite fall (between 2 April and 7 August 2007) prior to treatment; efficacy after flumethrin treatment (Group A) between 7 August and 26 November; after five consecutive oxalic acid treatments (Group B) in the periods 7 - 22 August, 22 - 28 August, and 28 August - 26 November; and cumulative treatment efficacy after treatment from 7 August to 26 November. Bars indicate standard deviation; asterisks indicate significantly (Tukey tests: $P<0.05$ ) higher mite mortality in comparison to paired group colonies in the same time period; $\mathrm{NM}=$ natural mortality; $\mathrm{CM}=$ cumulative treatment efficacy.

Natural mite mortality in the pre-treatment period of 66 days in 2008 , was $0.36( \pm 0.71)$ per day. Flumethrin strips applied to the Group A colonies produced a mean mite mortality of $65.14( \pm 83.66)$ per colony. Group B colonies received four oxalic acid treatments in the same period with a mean mite mortality of $64.83( \pm 62.82)$. Amitraz fumigations applied to previously flumethrin and oxalic acid treated colonies produced mite mortalities of 693.64 $( \pm 765.47)$ and $194.22( \pm 130.13)$, respectively. Coumaphos was used as a final control treatment for evaluation of the previous treatments. During the pretreatment period of 66 days, natural mite mortality represented $5.29 \%( \pm 8.75)$ of the total mite fall during the experiment. Flumethrin application on 25 July resulted in a drop of $12.52 \%( \pm 17.03)$ of the mite population, while four oxalic acid applications produced a mite-drop of 
$24.13 \%( \pm 13.95)$ of total mites. In all of the treated colonies, 4 amitraz fumigations produced a mean mite reduction of $93.82 \%( \pm 9.41)$. The percentage of fallen mites in the oxalic acid treated colonies between 25 July and 21 August was significantly $(P<0.05)$ higher than in those treated with flumethrin (fig. 2). The number of fallen mites during the experiments in both years ranged from 95 to 5392 mites (mean of 988.66) in 2007 and from 19 to 3782 mites (mean of 614.69) in 2008.

\section{Treatment efficacy}

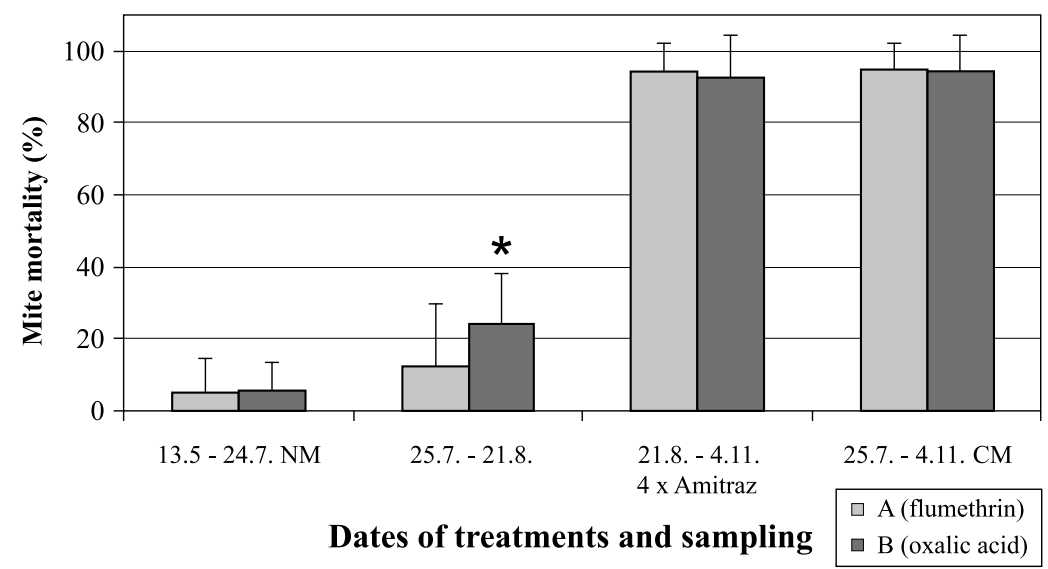

Fig. 2. Relative mite mortality in colonies of Group A during the pre-treatment period and after the flumethrin or oxalic acid treatments and followed by four amitraz fumigations. Flumethrin and four oxalic acid treatments to colonies in Groups A and B, respectively, is shown for the period 25 July - 21 August 2008. The asterisk indicates that Tukey tests established significantly $(P<0.05)$ higher mite mortality with four oxalic acid treatments compared to flumethrin. In other treatment periods there were no significant differences between treatment groups. NM = natural mortality; $\mathrm{CM}=$ cumulative mortality.

\section{Discussion}

The mean natural mite mortality as an indicator of the mite population (Liebig et al. 1983) was less than one per day during the spring, varying from 0.06 to 3.49 and from 0.01 to 3.79 per day in 2007 and 2008 , respectively. It has been found that this level of natural mite mortality allows the successful use of alternative mite control treatments such as oxalic acid A or thymol (Gregorc and Planinc 2005). It has also been found that in colonies with a low infestation level, fluvalinate and flumethrin were effective enough to allow colony survival during the winter (Gregorc and Smodiš Škerl 2007). The number of mites fallen from our experimental colonies during the present study indicates a moderate level of overall infestation, thus allowing the use of less effective control treatments.

The results from 2007 show that flumethrin was more effective than just one oxalic acid treatment, but after additional two oxalic acid treatments, the efficacy of both treatments was comparable. In 2008, the number of mites fallen from the colonies differed in both colony groups, but three oxalic acid treatments gave a higher efficacy compared to flumethrin. Oxalic acid treatment gave predictive efficacy in the period when the brood is present as was shown in experiments where three oxalic acid applications in August produced an efficacy of 24\% (Gregorc and Planinc 2004a), three oxalic acid applications in September when the colony development is retarded produced an efficacy of 37\% (Gregorc and Planinc 2002), and an efficacy of $24 \%$ was achieved after one oxalic acid treatment (Bródsgaard 
et al. 1999) administered by trickling in spring. In broodless colonies, $99 \%$ efficacy was achieved with oxalic acid (Imdorf et al. 1997). Due to its high efficacy, oxalic acid is thus considered as a final control treatment for the evaluation of previous colony treatments (Gregorc and Planinc 2004b) similar to coumaphos (Trouiller 1998). Flumethrin treatment demonstrated insufficient efficacy for mite reduction, being approximately $73 \%$ in 2007 , but only $13 \%$ in 2008 , not even comparable to oxalic acid treatments performed during the brood season (Rademacher and Harz 2006). The increased resistance of mites to synthetic active ingredients has been observed (Spreafico et al. 2001), and the improper use of acaricides could result in increased mortality of honey bee colony.

Amitraz fumigation performed after less effective treatments by flumethrin or oxalic acid produced $95 \%$ reduction of mites in the colonies. However, it is essential to ensure normal colony development and overwintering. The use of flumethrin at these low efficacies should be superseded by organic treatments such as oxalic acid trickling.

The efficacy of the flumethrin and oxalic acid treatments that we applied are underestimated because mite reproduction within the honey bee colonies and mite re-invasion from both control and neighboring colonies were not taken into account. Further experiments should be conducted in order to establish how to increase the efficacy of mite control in highly-infested colonies during the period of brood rearing under continental climatic conditions, as it has been demonstrated that synthetic acaricides should be constantly reevaluated.

\section{Acknowledgements}

We thank Marjan Kokalj and Vesna Lokar for their technical help and assistance. The work was supported by both the Slovenian Ministry of Higher Education, Science and Technology and the Ministry of Agriculture, Forestry and Food (Research program P4-0133 and projects V4-0484 and V4-1078).

\section{References}

Brødsgaard CJ, Jansen SE, Hansen CW, Hansen H 1999: Spring treatment with oxalic acid in honey bee colonies as varroa control. DIAS report no. 6 Horticulture 1999: 16

Charriere JD, Imdorf A 2002: Oxalic acid treatment by trickling against Varroa destructor: recommendations for use in central Europe and under temperate climate conditions. Bee World 83: 51-60

Elzen PJ, Baxter JR, Spivak M, Wilson WT 2000: Control of Varroa jacobsoni Oud. resistant to fluvalinate and amitraz using coumaphos. Apidologie 31: 437-441

Floris I, Cabras P, Garau VL, Minelli EV, Satta A, Troullier J 2001: Persistence and effectiveness of pyrethroids in plastic strips against Varroa jacobsoni (Acari: Varroidae) and mite resistance in a Mediterranean area. J Econ Entomol 94: 806-810

Gregorc A, Planinc I 2001: Acaricidal effect of oxalic acid in honey bee (Apis mellifera) colonies. Apidologie 32: $333-340$

Gregorc A, Planinc I 2002: The control of Varroa destructor using oxalic acid. Vet J 163: 306-310

Gregorc A, Planinc I 2004a: Using oxalic acid for varroa mite control in honey bee colonies during the beekeeping season (Uporaba oksalne kisline za zatiranje varoj v čebeljih družinah v čebelarski sezoni). Slov Vet Res 41: $35-39$

Gregorc A, Planinc I 2004b: Dynamics of falling varroa mites in honey bee (Apis mellifera) colonies following oxalic acid treatments. Acta Vet Brno 73: 385-391

Gregorc A, Planinc I 2005: The control of Varroa destructor in honey bee colonies using the thymol based acaricide, Apiguard. Am Bee J 145: 672-675

Gregorc A, Poklukar J 2003: Rotenone and oxalic acid as alternative acaricidial treatments for Varroa destructor in honey bee colonies. Vet Parasit 111: 351-360

Gregorc A, Smodiš Škerl MI 2007: Combating Varroa destructor in honeybee colonies using flumethrin or fluvalinate. Acta Vet Brno 76: 309-314

Imdorf A, Charriere JD, Bachofen B 1997: Efficiency checking of the Varroa jacobsoni control methods by means of oxalic acid. Apiacta 32: 89-91

Imdorf A, Charriere JD, Maquelin C, Kilchenmann V, Bachofen B 1996: Alternative varroa control. Am Bee J 136: $189-193$

Liebig G, Schlipf U, Fremuth W, Ludwig W 1983: Ergebnisse der Untersuchungen über die Befallsentwicklung der Varroa-Milbe in Stuttgart-Hohenheim. Allg Imkerz 18: 185-190

Lodesani M, Colombo M, Spreafico M 1995: Ineffectiveness of Apistan ${ }^{\circledR}$ treatment against the mite Varroa jacobsoni Oud in several districts of Lombardy (Italy). Apidologie 26: 67-72 
Melathopoulos AP, Gates J 2003: Comparison of two thymol-based acaricides, Api Life Var (R) and Apiguard (TM), for the control of varroa mites. Am Bee J 43: 489-493

Milani N 1999: The resistance of Varroa jacobsoni Oud. to acaricides. Apidologie 30: 229-234

Mutinelli F, Baggio A, Capolongo F, Piro R, Prandin L, Biasion L 1997: A scientific note on oxalic acid by topical application for the control of arouses. Apidologie 28: 461-462

Rademacher E, Harz M 2006: Oxalic acid for the control of varroosis in honey bee colonies - a review. Apidologie 37: $98-120$

Radetzki T 1994: Oxalsäure eine weitere organische Säure zur Varroabekämpfung. Allg Dtsch Imkerztg 2: $11-15$

Sammataro D, Gerson U, Needham G 2000: Parasitic mites of honey bees: life history, implications and impact. Ann Rev Entomol 45: 519-548

Spreafico M, Eördegh FR, Bernardinelli I, Colombo M 2001: First detection of populations of Varroa destructor Oud resistant to coumaphos. Results of laboratory tests and field trials. Apidologie 32: 49-55

Trouiller J, 1998: Monitoring Varroa jacobsoni resistance to pyrethroids in Western Europe. Apidologie 29: $537-546$

Wallner K 1999: Varroacides and their residues in bee products. Apidologie 30: 235-248

Watkins M 1997: Resistance and its relevance to beekeeping. Bee World 78: 15-22

Witherell PC, Herbert EW 1988: Evaluation of several possible treatments to control Varroa treatments to control Varroa mite Varroa jacobsoni (Oud.) on honey bees in packages. Am Bee J 128: 441-445 